\title{
Élisabeth Germain (éd.), Tchad : un appel, une aventure partagée
}

Paris, L'Harmattan, 2005, 223 p.

Clémence Bosselut

\section{(2) OpenEdition}

\section{Journals}

Édition électronique

URL : http://journals.openedition.org/assr/6232

DOI : 10.4000/assr.6232

ISSN : $1777-5825$

\section{Éditeur}

Éditions de l'EHESS

Édition imprimée

Date de publication : 1 juin 2007

Pagination : $97-251$

ISBN : 978-2-7132-2143-9

ISSN : 0335-5985

\section{Référence électronique}

Clémence Bosselut, « Élisabeth Germain (éd.), Tchad: un appel, une aventure partagée », Archives de sciences sociales des religions [En ligne], 138 | avril - juin 2007, document 138-44, mis en ligne le 12 septembre 2007, consulté le 21 septembre 2020. URL : http://journals.openedition.org/assr/6232 DOI : https://doi.org/10.4000/assr.6232

Ce document a été généré automatiquement le 21 septembre 2020

(C) Archives de sciences sociales des religions 


\section{Élisabeth Germain (éd.), Tchad : un appel, une aventure partagée}

Paris, L'Harmattan, 2005, 223 p.

\section{Clémence Bosselut}

1 Cet ouvrage est un dossier rassemblant des lettres, documents et témoignages d'auxiliaires du sacerdoce envoyées au Tchad, entre 1958 et 2003. Il se donne pour objectif de «retracer l'engagement de la Congrégation» dans la jeune Église tchadienne et d'«évoquer la richesse de vie que les auxiliaires ont pu donner et recevoir ». Le lecteur est d'emblée prévenu qu'« il ne s'agit que d'un essai » incomplet.

2 Après un bref rappel de l'histoire de la mission, la description de la jeune Église tchadienne et de la situation du Tchad, l'auteur relate «l'aventure» des Sœurs dans l'Église tchadienne. Les lettres d'époque et les récits rétrospectifs récents des sœurs auxiliaires sont généralement concrets, descriptifs et simples. De nombreuses données factuelles et des chiffres sont fournis. L'ensemble permet de se représenter ce qu'ont pu être les vies de ces femmes. La description précise de leurs conditions de vie, des départs et arrivées de chacune, de leurs difficultés, réussites et doutes participent de la construction de la mémoire communautaire. Les exercices individuels de "relecture " de leurs missions sont passionnants. Les extraits de discours d'évêques ou de prêtres, français ou tchadiens, montrent les liens unissant les différents protagonistes de l'histoire de cette Église.

Le nombre et la variété des points abordés témoignent de la richesse de la réflexion de cette communauté sur sa présence en Afrique. Interroger ainsi la mémoire de communautés telles que celle des auxiliaires invite à mettre en perspective la façon dont la mission se vit actuellement dans l'Église française et le rapport entre les Églises africaines et européennes. Les questions soulevées restent totalement actuelles: l'articulation entre mission et développement, le rôle des laïcs, la place de la religion traditionnelle, le rapport à la politique, aux institutions locales et au pouvoir... Le problème de l'inculturation est particulièrement passionnant puisque dans leur quotidien, les sœurs étaient directement en contact avec la population, et devaient 
donc se positionner sans cesse par rapport aux traditions locales, à l'islam, aux valeurs traditionnelles et aux langues locales.

4 L'auteur a pris volontairement une position très discrète en laissant généralement les lettres et discours parler d'eux-mêmes. Il s'agit d'une première étape qui permet à la communauté des sœurs de se constituer une mémoire facilement accessible. On aimerait cependant en savoir plus : comment se sont faits les ajustements au quotidien, entre la culture locale et cette Église catholique ? Comment a-t-on géré les frottements entre ces missionnaires et les jeunes prêtres tchadiens. Comment analyser les négociations entre les sœurs, la culture locale tchadienne et cette nouvelle Église catholique tchadienne? Ces questions sont simplement effleurées. Reste à tirer un bilan plus complet de ces années de présence pour l'ensemble de la communauté, audelà des relectures personnelles des sœurs. Il y aurait également un meilleur parti à tirer des photos, qui sont généralement utilisées simplement pour illustrer. Ce sont de vraies images d'archives qui, si elles étaient plus systématiquement datées et expliquées, pourraient aider l'historien à analyser la situation.

Cet ouvrage est un beau travail de mémoire. L'étape suivante serait donc de s'emparer de ces riches matériaux pour les analyser et les mettre en perspective. 